\title{
A importância da academia, da escola e dos professores para a consolidação do ensino de gramática em três eixos
}

\author{
Marcus Vinicius Souza de OLIVEIRA (1) \\ Universidade Estadual do Rio de Janeiro (UERJ)
}

RESUMO

Este texto pretende resenhar a conferência Ensino de gramática em três eixos: uma questão de ciência, cidadania e respeito linguístico proferida pela Professora Silvia Rodrigues Vieira na série Abralin ao vivo no dia 16 de julho de 2020. Nesta apresentação, a professora destaca como a proposta experimental do ensino de gramática em três eixos se relaciona com o desenvolvimento do pensamento científico, com a promoção da cidadania e

OPEN ACCESS

EDITADO POR

Raquel Freitag

AVALIADO POR Isabel de Oliveira e Silva Monguilhott

DATAS Recebido: 23/07/2020 Aceito: $07 / 08 / 2020$ Publicado: 13/08/2020

COMO CITAR com o respeito linguístico. Conforme a proposta, o Eixo 1 pressupõe um trabalho inteligente de sistematização gramatical, descrevendo a linguagem a partir do caráter sistemático das construções. O Eixo 2 reconhece os elementos gramaticais como matérias produtoras de sentido, permitindo reafirmar a desejável articulação entre o ensino de gramática e as atividades de leitura e produção de textos. Já o Eixo 3 propicia reflexões sobre as estruturas que o aluno não conhece - por não pertencerem à variedade que ele domina.

\section{ABSTRACT}

This text intends to review the conference Grammar teaching in three axes: a question of science, citizenship and linguistic respect given by Professor Silvia Rodrigues Vieira in the Abralin series live on July 16, 2020. In this presentation, the teacher highlights how the experimental proposal of grammar teaching in three axes is related to the development of scientific thinking, the promotion of citizenship and linguistic respect. According to 


\section{REVISTA DA ABRALIN}

the proposal, Axis 1 presupposes an intelligent work of grammatical systematization, describing language based on the systematic character of constructions. Axis 2 recognizes grammatical elements as materials that produce meaning, allowing to reaffirm the desirable articulation between the teaching of grammar and the activities of reading and producing texts. Axis 3, on the other hand, provides reflections on the structures that the student does not know - as they do not belong to the variety he dominates.

\section{PALAVRAS-CHAVE}

Ensino de gramática. Gramática e produção de sentido.

Norma e variação.

\section{KEYWORDS}

Grammar teaching. Grammar and production of meaning.

Norm and variation

No dia 16 de julho de 2020, a professora Silvia Rodrigues Vieira proferiu a conferência Ensino de gramática em três eixos: uma questão de ciência, cidadania e respeito linguístico no evento Abralin ao vivo. Em sua apresentação, Vieira esclarece que dois projetos de pesquisa a credenciam para falar sobre o tema: o GT Sociolinguística da ANPOLL (Eixo Variação, norma e ensino) e sua atuação na disciplina Gramática, variação e ensino oferecida pelo Mestrado Profissional em Letras (PROFLETRAS) na UFRJ - onde idealizou e implementou a proposta ora apresentada.

A apresentação é dividida em quatro partes: panorama do ensino de gramática a partir dos PCN; explanação da proposta do ensino de gramática em três eixos (ensino de gramática e não ensino de língua); apresentação de algumas pesquisas na área do ensino de gramática (aplicação dos 3 eixos e abordagem científica do trabalho explícito com gramática), indicando que alguns resultados já permitem considerar o ensino de gramática como área de pesquisa científica; e considerações finais.

Na parte introdutória da conferência, Vieira enfatiza que as pesquisas sobre o ensino de gramática (uma velha questão no que diz respeito ao pensamento e ao tempo em que isso vem sendo estudado, mas também uma questão atual, tendo em vista que muitas perguntas ainda não foram respondidas) já têm resultados científicos a compartilhar, o que é positivo, já que o tema é de extrema relevância social e do interesse antigo e atual de linguistas, educadores e de todos os cidadãos.

A pesquisa sobre o ensino de gramática apresenta, segundo a autora, alguns desafios, como o fato de ser um tema interdisciplinar que permite abordagens teóricas distintas, ou ainda a difícil tarefa de se construir uma abordagem original. Outro desafio apresentado por Vieira é a dificuldade de diálogo entre orientações científicas muito diversas - que observam os fatos gramaticais sob aspectos muito diferentes - e as controvérsias por vezes apaixonadas de cada parte. De acordo com 


\section{REVISTA DA ABRALIN}

ela, deve-se falar em ensino de gramática baseado no que diz a CIÊNCIA, sensível ao que é o ensino de LP como um todo e respeito a todas as linhas científicas e à sociedade (pelo que ela espera do ensino de Língua Portuguesa nos doze anos que compõem a educação básica).

Vieira faz uma breve análise de como o ensino de gramática está posto na Base Nacional Comum Curricular (BNCC). Segundo o documento, o ensino de língua portuguesa deve ser fundamentado em análise linguística/semiótica, leitura, produção e oralidade e, dependendo do olhar que se tem sobre essas quatro partes, olha-se para o ensino de gramática de uma maneira (ensino de gramática a serviço de algo, decorrente de algo ou aliado a algo).

Sobre o ensino de gramática após o advento dos PCN, a professora afirma que o componente linguístico-gramatical, do ponto de vista teórico-conceitual, ganhou um caráter instrumental a serviço das práticas de linguagem, já que o documento orienta explicitamente que o ensino deve se dar numa abordagem sócio-interacional e o texto deve ser objeto privilegiado do ensino. Mesmo advogando que o ensino deve se dar a partir do esquema USO-REFLEXÃO-USO e que a abordagem gramatical seja feita em atividades linguísticas, epilinguísticas e metalinguísticas, não se desenvolveu um quadro alternativo ao da abordagem tradicional, sobretudo no plano da sentença.

Por outro lado, enxerga-se como positivo o fato de o documento assumir a legitimidade da variação linguística, sem deixar de ressaltar o compromisso da escola com a promoção da "variedade urbana culta de prestígio" / "padrão culto escrito".

Ao iniciar a abordagem dos três eixos para o ensino de gramática, Vieira questiona: "Que concepções de língua/gramática interessam ao ensino?". Como toda língua se caracteriza por ser sistemática, interativa e heterogênea, a professora afirma que essas propriedades não podem ser desmerecidas na sala de aula, devendo receber a mesma atenção. A partir dessa afirmação, constrói a proposta para o ensino de gramática em três eixos: Eixo 1 - Gramática e atividade reflexiva, Eixo 2 Gramática e produção de sentido e Eixo 3 - Gramática e norma/variedades.

Cada eixo deve ser trabalhado de acordo com alguns questionamentos sobre o tema gramatical a ser abordado. O Eixo 1, por exemplo, deve partir da reflexão sobre quais elementos/conceitos em termos teórico-descritivos devem ser do domínio consciente do aluno para que o tratamento desse tema gramatical seja bem trabalhado. Já para o Eixo 2 é preciso estabelecer a relação entre esse tema gramatical e a produção de sentidos, seja no âmbito da leitura ou da produção de enunciados - pois todo tema gramatical está correlacionado à produção de sentidos. No eixo 3 , deve-se considerar se o tema gramatical se relaciona ao domínio de normas frente à realidade da variação linguística, se é um tema de regra variável e como se dá a relação entre esse componente gramatical com a expressão de uso e de padrão. Vieira destaca o fato de que o eixo 1 é transversal aos outros, não sendo possível, portanto, abordar os outros eixos sem estar fundamentado numa abordagem reflexiva da gramática.

Como se trata de uma atividade interdisciplinar, Vieira expõe brevemente como algumas correntes teóricas podem atuar em cada um dos eixos. O Eixo 1, por exemplo, na análise de fenômenos gramaticais e na abordagem consciente da gramática pode ser trabalhado por abordagens formalistas, cognitivas, psicolinguísticas. O trabalho com recursos expressivos na construção dos sentidos do texto, no âmbito do Eixo 2, as abordagens formalistas, funcionalistas, textuais e discursivas podem 


\section{REVISTA DA ABRALIN}

fazer parte da pesquisa. Para o Eixo 3, abordagens que levam em conta a análise de fenômenos gramaticais como manifestação de normas/variedades (cultas e populares) com base nos contínuos de oralidade-letramento/modalidade; monitoração estilística/registro.

Vieira relaciona o Eixo 3 à pedagogia da variação linguística. Para ela, o eixo Ensino de gramática, norma/variações contribui para que o aluno compreenda a língua como um fenômeno heterogêneo, posicione-se positivamente em relação ao dialeto do seu grupo social e invista em práticas de letramento que os levem a dominar também a variedade culta da língua. Além disso, esse eixo deve abordar explicitamente a diversidade linguística e a avaliação social que recobre a variação quando tratamos dos usos orais e escritos da língua, além de reconhecer que os instrumentos normativos precisam refletir a norma efetivamente praticada, pois mesmo as variedades cultas são diversificadas e heterogêneas.

Em relação às concepções de gramática, o conhecimento linguístico-gramatical do aluno (gramática interna) deve ser ponto de partida para a reflexão linguística e a sistematização das descrições de objetos teóricos e de usos (gramática externa), dando conta dos objetos descritivos e prescritivos. Na escola, a abordagem explícita da gramática (externa) não é totalmente explorada. Em um quadro esquemático, a autora argumenta que a abordagem teórico-descritiva é sincrônica em termos de orientação e tradicional em termos de fundamento teórico, com alguma incursão de dispositivos discursivotextuais e pouquíssima incursão de fundamentos de outras áreas (como formalismo e funcionalismo). Em relação à abordagem descritiva, predomina apenas a orientação tradicional.

Em relação à abordagem dos objetos teórico/conceituais, a professora afirma que nenhum quadro teórico-descritivo dá conta sozinho de todos os objetivos e desafios do ensino de gramática; por isso, é preciso, sempre que possível, conciliar as contribuições de cada quadro de acordo com os objetivos que se pretendem alcançar (inclusive as contribuições da GT)

Em relação à abordagem dos objetos de uso, Vieira salienta que a descrição deve partir de resultados científicos (considerando os contínuos de variação em termos de modalidade, registro e variedade) e que as orientações normativas para o emprego da língua contemporânea em termos de padronização devem partir da descrição, e não da "norma gramatical", que deve ser estudada como valor cultural e auxiliar para a compreensão de textos.

Como o ensino de gramática precisa ser um objeto científico, com desenvolvimento de práticas metodológicas envolvendo professores-pesquisadores, a professora destaca positivamente as pesquisas desenvolvidas no Mestrado Profissional em Letras. Todavia, ressalta que a metodologia de pesquisa ainda precisa ser mais desenvolvida e consolidada a partir de aportes metodológicos variados que permitam avaliar/mensurar/observar o êxito do processo ensino-aprendizagem. Segundo ela, a replicabilidade das pesquisas é o que precisa de mais desenvolvimento.

Vieira finaliza afirmando que, embora ainda seja necessário resolver alguns problemas de inconsistências teóricas, já há resultados científicos promissores de sistematização conceitual e descritiva para o ensino de gramática como objeto de pesquisa, e o êxito de algumas atividades na construção de estratégias pedagógicas envolvendo os três eixos no desenvolvimento de metodologias de pesquisa comprovaria isso. 


\section{REVISTA DA ABRALIN}

Os objetivos para o ensino de gramática estariam relacionados, então ao desenvolvimento do raciocínio científico, à possibilidade de acesso consciente de todo cidadão a práticas de letramento significativas e à promoção do maior número possível de variantes linguísticas, capacitando o aluno a reconhecê-las e/ou produzi-las caso deseje.

Finaliza destacando o papel do professor (e do Profletras) para a viabilidade dessas pesquisas, pois, segundo ela, o professor é "a pessoa mais indicada para desenvolver, experimentar e avaliar os métodos para o ensino cientificamente embasado, porque é o analista habilitado a avaliar o que efetivamente funciona em sala de aula, no exercício do papel de PROFESSOR-PESQUISADOR".

\section{REFERÊNCIAS}

ENSINO de gramática em três eixos: uma questão de ciência, cidadania e respeito linguís-tico por Silvia Vieira Rodrigues [s.l., s.n], 2020. 1 vídeo (2h 02min 45 s). Publicado pelo canal da Associação Brasileira de Linguística. Disponível em <https://www.youtube.com/watch?v=ypVJ2tVT3Yw> Acesso em: 16 jul 2020. 